\title{
Crystalline silica exposure and lung cancer mortality in diatomaceous earth industry workers: a quantitative risk assessment
}

\author{
F L Rice, R Park, L Stayner, R Smith, S Gilbert, H Checkoway
}

\begin{abstract}
Objective-To use various exposureresponse models to estimate the risk of mortality from lung cancer due to occupational exposure to respirable crystalline silica dust.

Methods-Data from a cohort mortality study of 2342 white male California diatomaceous earth mining and processing workers exposed to crystalline silica dust (mainly cristobalite) were reanalyzed with Poisson regression and Cox's proportional hazards models. Internal and external adjustments were used to control for potential confounding from the effects of time since first observation, calendar time, age, and Hispanic ethnicity. Cubic smoothing spline models were used to assess the fit of the models. Exposures were lagged by 10 years. Evaluations of the fit of the models were performed by comparing their deviances. Lifetime risks of lung cancer were estimated up to age 85 with an actuarial approach that accounted for competing causes of death.
\end{abstract}

Results-Exposure to respirable crystalline silica dust was a significant predictor $(p<0.05)$ in nearly all of the models evaluated and the linear relative rate model with a 10 year exposure lag seemed to give the best fit in the Poisson regression analysis. For those who died of lung cancer the linear relative rate model predicted rate ratios for mortality from lung cancer of about 1.6 for the mean cumulative exposure to respirable silica compared with no exposure. The excess lifetime risk (to age 85) of mortality from lung cancer for white men exposed for 45 years and with a 10 year lag period at the current Occupational Safety and Health Administration (OSHA) standard of about $0.05 \mathrm{mg} / \mathrm{m}^{3}$ for respirable cristobalite dust is $19 / 1000$ (95\% confidence interval (95\% CI) $5 / 1000$ to $46 / 1000$ ).

Conclusions-There was a significant risk of mortality from lung cancer that increased with cumulative exposure to respirable crystalline silica dust. The predicted number of deaths from lung cancer suggests that current occupational health standards may not be adequately protecting workers from the risk of lung cancer.

(Occup Environ Med 2001;58:38-45)

Keywords: crystalline silica; cristobalite; lung cancer
Although the non-malignant respiratory health hazards of occupational exposure to dust have been known for centuries, the possibility of an association of occupational exposure to respirable crystalline silica dust with lung cancer has been debated in the scientific literature in recent decades. In 1996, a Working Group of the World Health Organization's International Agency for Research on Cancer (IARC) reviewed the results of published epidemiological studies of occupational exposure to crystalline silica and lung cancer, and concluded that there is "sufficient evidence in humans for the carcinogenicity of inhaled crystalline silica in the form of quartz or cristobalite from occupational sources". The debate is important internationally for public health because crystalline silica dust is a common and worldwide occupational exposure, and a designation of carcinogenicity would be likely to result in lower concentrations of silica allowed in workplace exposure.

Few epidemiological studies of workers with occupational exposure to respirable crystalline silica have collected quantitative exposure data appropriate for an exposure-response analysis and often there were potentially confounding exposures. The data on mortality and exposure to dust gathered during a recent follow up study of diatomaceous earth mining and processing workers in California ${ }^{2}$ were relatively unconfounded by other exposures. For the study follow up period (1942-94), Checkoway et al reported significantly increased rate ratios for mortality from lung cancer (rate ratio $=2.15 ; 95 \%$ confidence interval $(95 \% \mathrm{CI})$ 1.08 to 4.28 ; 15 year exposure lag) and non-malignant respiratory disease (rate ratio $=5.35 ; 95 \%$ CI 2.23 to $12.8 ; 15$ year exposure lag) in the highest compared with the lowest stratum of cumulative exposure to respirable crystalline silica. ${ }^{2}$

The present study is an exposure-response analysis and quantitative risk assessment of mortality from lung cancer based on data from the same cohort of diatomaceous earth workers.

\section{Methods}

STUDY POPULATION

The study population described in the original mortality study ${ }^{2}$ included 2342 white men employed at a diatomaceous earth mining and processing facility in Lompoc, California for at least 12 months of cumulative service and at least 1 day between 1 January 1942 and 31 December 1987. The cohort was restricted to workers who did not have known exposure to asbestos from previous employment. About a 
quarter of the cohort was made up of white Hispanic men. The cohort was followed up from 1 January 1942 to 31 December 1994. Seventy seven deaths from cancer of the trachea, bronchus, or lung occurred in that period. All causes of death were assigned the international classification of diseases (ICD) codes in effect at the time of death.

RETROSPECTIVE EXPOSURE ASSESSMENT

A strength of this study is the availability of relatively high quality information on exposure for estimating historical occupational crystalline silica exposures, and the absence of exposures to radon progeny, arsenic, and diesel exhaust. Also, exposure to asbestos was accounted for in the analysis. ${ }^{23}$ Calcining of the ore extracted from the open pit diatomaceous earth mines produced a final product containing $10 \%-25 \%$ crystalline silica, mainly in the form of cristobalite. ${ }^{24}$ The crystalline silica content of uncalcined diatomaceous earth is about $1 \%$ in the form of quartz. ${ }^{2}$

Quantitative dust exposure was estimated with complex methods described elsewhere ${ }^{5}$ and summarised here. More than 6000 measurements of exposure to dust taken by the company from 1948-88 were available. Particle count data before 1962 (million particles per cubic foot) were converted to gravimetric units $\left(\mathrm{mg} / \mathrm{m}^{3}\right)$ with linear regression modelling. $\mathrm{Cu}-$ mulative exposures to respirable crystalline silica dust were estimated for each worker by linking the historical occupational hygiene data with detailed employment records. ${ }^{2}$ Mean cumulative concentrations of respirable dust and respirable crystalline silica dust were $7.31 \mathrm{mg} / \mathrm{m}^{3}$.years (maximum: $168.84 \mathrm{mg} / \mathrm{m}^{3}$.years) and 2.16 $\mathrm{mg} / \mathrm{m}^{3}$.years (maximum: $62.52 \mathrm{mg} / \mathrm{m}^{3}$.years), respectively. ${ }^{2}$ The mean concentration of respirable crystalline silica averaged over the cohort's years of employment was $0.29 \mathrm{mg} / \mathrm{m}^{3}$.

Chrysotile asbestos was used at various times in two small operations between the 1920s and 1977. Quantitative estimates of exposure to asbestos (fibres $/ \mathrm{ml}$ ) for the years since 1930 for all workers in the cohort were based on historical exposure monitoring data for jobs with direct handling of asbestos, production records, and documented quantities of asbestos contained in various mixed products. Asbestos exposures for years of employment before 1930 were extrapolated from job specific intensity estimates for $1930 .^{2}$ Cumulative exposure to asbestos (fibres/ml.years) was calculated in the same manner as the silica exposure metric. The mean cumulative concentration of asbestos fibres was 1.44 fibres/ ml.years (maximum: 97.55 fibres $/$ ml.years). ${ }^{2}$

DATA ANALYSIS

Poisson regression

Previously constructed demographic and work history files were obtained for the diatomaceous earth cohort. The work history file contained a complete sequence of job assignments with dates and estimated exposure concentrations for total dust, crystalline silica (as cristobalite), and asbestos dusts. Smoking information, available for only one half of the study population, was not used in final analyses. From the work history file, annual summary cumulative exposures were calculated for total, silica, and asbestos dusts during the period 1942-94. A computer software package, Epicure DATAB, version $2.06,{ }^{6}$ was used to generate files for Poisson regression analysis. Personyears were counted from when a worker met the study requirements until he was lost to follow up, died, or reached the end of follow up. The person-years and deaths were stratified by cumulative exposure to silica, time since first being observed, calendar time, age, and Hispanic ethnicity. Fifty levels of cumulative exposure to silica were formed, as well as a non-exposed level, with stratum widths that gradually increased, beginning with $0.33 \mathrm{mg} /$ $\mathrm{m}^{3}$.years at low cumulative exposures where the population was dense, and ending with 2.2 $\mathrm{mg} / \mathrm{m}^{3}$.years at maximum cumulative exposure where there was very little observation time. The choice of 50 levels was made after observing improving model fit with 5, 10, 20, and 50 levels, and noting a relatively small improvement (the change in deviance resulting from adding the exposure term) with the step from 20 to 50 . Although 50 may seem like many levels, their use provided more richly detailed information for fitting the continuous models than would much fewer levels. The convergence found when 50 levels were used was affirmed by obtaining similar results from analyses with the Cox's proportional hazards model. Mean cumulative exposures from the 50 levels were then modelled as a continuous variable to evaluate exposure effects. Time since first observation was classified in three levels $(<10,10-19, \geqslant 20$ years), calendar time in nine levels (<1955, 1955-1959, . . ., 1990-1994), and age in 13 levels (15-24, $25-29,30-34$, . . ., $75-79, \geqslant 80$ years). Hispanic ethnicity was included as a binary variable in the models because of known lower risks of lung cancer among Hispanic white men than among non-Hispanic white men. ${ }^{7}$

Poisson regression models were fitted with the AMFIT program of Epicure (version 2.06). Alternative model forms were evaluated to detect a wide range of possible exposureresponse patterns including linear, sublinear, and supralinear. ${ }^{8}$ Both relative rate $\left(\lambda=\lambda_{0} \times f(E)\right)$ and additive excess rate $\left(\lambda=\lambda_{0}+\mathrm{f}(\mathrm{E})\right)$ models were fitted to the data. Where $\lambda$ is the predicted incidence rate, $f(E)$ is a function of cumulative silica dust exposure in $\mathrm{mg} / \mathrm{m}^{3}$.years, and $\lambda_{0}$ is the background incidence rate. The following model forms were evaluated:

Log linear: $R R=\exp \left(\beta_{1} E\right)$

Log square root: $R R=\exp \left(\beta_{1} \mathrm{E}^{0.5}\right)$

Log quadratic: $R R=\exp \left(\beta_{1} \mathrm{E}+\beta_{2} \mathrm{E}^{2}\right)$

Power: $R R=(1+E)^{\beta_{1}}$

Linear relative rate: $R R=1+\beta_{1} E$

Shape $(\alpha): R R=1+\beta_{1} E^{\alpha}$

Additive excess rate: $\mathrm{AER}=\beta_{1} \mathrm{E}$

where $\beta_{1}, \beta_{2}$, and $\alpha$ are parameters associated with cumulative crystalline silica exposure E, $\mathrm{RR}=$ relative rate, and $\mathrm{AER}=$ additive excess rate.

The background incidences were modelled with stratification on time since first being 
observed calendar time, age, and ethnicity (Hispanic $v$ non-Hispanic). Also, to improve the estimation of precision, external standardisation on calendar time and age was accomplished with United States rates for mortality from lung cancer during $1940-94^{9}$ as a multiplier of observation time (person-years) in the Poisson regression. This resulted in models of standardised rate ratios, which, stratified on ethnicity (2 levels) and time since first being observed (3 levels), allowed for six independent background rates and therefore were partially adjusted for differences between the study population and United States reference populations (ethnicity, healthy worker survivor effect).

Cox's proportional hazards model

The Cox's proportional hazards model was used as an alternative method for evaluating exposure-response models (1a-1d already described). Analytical files were constructed from the original detailed work history file from a FORTRAN program (created for this study). Attained age was the time dimension for the baseline hazard, which, together with stratifying variables, was used to form matching risk sets. Proportional hazards models were fitted with the SAS procedure PHREG ${ }^{10}$ configured for a matched logistic regression analysis and were stratified on time since first being observed, calendar time, and ethnicity in the same way as the Poisson regression analyses. To improve estimation precision, as in the Poisson regression models, external standardisation was performed on calendar time and age by including United States rates for mortality from lung cancer as an offset in the Cox's models.

\section{Final models}

Unlagged and lagged $(2,5,8,10,12$, and 15 year periods) cumulative exposures were considered. A lag period of 10 years seemed to provide the best fit to the data after conducting Poisson and Cox modelling of data. Because results were similar, only the Poisson regression estimates are displayed in the tables. Informal comparisons of goodness of fit were performed by comparing the deviances (change in $-2 \ln ($ likelihood)) of these models. A formal comparison was not possible because the models were not nested or the data structures were distinct (Poisson versus Cox). The models with the smallest deviance were considered to have the best fit. Also, Poisson regression models 1a, $1 \mathrm{~b}$, and $1 \mathrm{~d}$ were evaluated by comparing the fit of these models with cubic smoothing spline models. The cubic smoothing spline model is a flexible basis for detecting smooth departures of the exposure-response from a specified form. These models were fitted with S-Plus version 4.5 as generalised additive models with about three degrees of freedom for the effect of exposure. ${ }^{1112}$

For the categorical model $\left(R R=\sum\left(\left(\beta_{k} I(e x-\right.\right.\right.$ posure category $=k)$ )) where: $\beta_{\mathrm{k}}$ are the parameters and $I()$ are indicator variables), five exposure categories were obtained by partitioning the continuous cumulative exposure. Potential interactions between exposure and other covariates, and higher order exposure terms (quadratic and cubic) were evaluated. From these statistical and graphical evaluations, a final functional form was chosen for modelling the relation between exposure to crystalline silica and the response variables.

Prediction of risks over a working lifetime Estimates of excess lifetime risk of death from lung cancer were developed for exposures to varying concentrations of crystalline silica dust based on an actuarial method developed for a risk analysis of exposures to radon. ${ }^{13}$ An advantage of this method is that it accounts for competing causes of death which act to remove a fraction of the population each year from the risk of death from lung cancer so that it is not necessary to assume that all workers would survive these competing causes to a given age. Excess risks associated with given silica concentrations were estimated for workers exposed during a 45 year occupational lifetime between the ages 20 and 65. (Forty five years is the occupational lifetime generally used by the Occupational Safety and Health Administration (OSHA) for risk assessment.) The annual risks were accumulated up to age 85 . Age specific background rates for lung cancer and for competing causes of death were derived from United States vital statistics for $1992^{14}$ (year of the most recently published national mortality data) for white men, white women, black men, black women, and the total population.

Evaluation of confounding by cigarette smoking Data on smoking habits (ever smoked $v$ never smoked) were collected since the 1960s for the company's radiographic screening programme and were available for 1171 of the subjects $(50 \%)$. However, for the 77 workers who died from lung cancer, most (50 deaths (64.9\%)) had unknown smoking habits. Thus, there are considerable gaps in these data that make evaluation of smoking problematic. In their exposure-response analysis, Checkoway et al examined smoking prevalence and cumulative exposure to silica by applying a method ${ }^{15}$ that estimated confounding bias in their observed rate ratios. The method $^{15}$ is an indirect approach for estimating the possible extent of confounding when there are no or limited data on the presumed confounder (cigarette smoking). The method involves estimating the prevalences of the confounder in the various groups compared, and assuming a relative risk for the association between the confounder and the disease under study, to estimate the relative risk that potentially could solely be due to confounding. The observed relative risk can then be adjusted by dividing it by the relative risk due to confounding. Application of the available estimates of ever smoked by cumulative exposure (lagged 15 years) category to the formula $^{15}(83 \%$ ever smoked in the highest exposed group and $63 \%$ in the reference category) and assuming a conservative relative risk of 20 for ever versus never smoked yielded an adjusted lung cancer rate ratio of 1.67 in the highest exposure stratum, which was lower than the observed rate ratio of 2.15 . Checko- 
Table 1 Exposure-response estimates of mortality for lung cancer and silica by Poisson regression comparing several specifications of exposure with lag of 10 years ( 77 lung cancer deaths)

\begin{tabular}{|c|c|c|c|c|c|c|c|}
\hline Model* & & $\beta_{1}$ Estimate & $\begin{array}{l}\text { Change } \\
\text { (-2ln } \\
\text { likelihood) }\end{array}$ & $p$ Valuet & $\begin{array}{l}R R \text { at } 1.0 \\
m g / m^{3} \cdot y \neq\end{array}$ & $\begin{array}{l}R R \text { at } \\
\text { meanS }\end{array}$ & $\begin{array}{l}R R \text { at } \\
\text { maximum } \mathbb{S}\end{array}$ \\
\hline \multicolumn{8}{|l|}{ Log linear (1a): } \\
\hline Internal adjustment & & 0.0508 & 4.946 & 0.026 & 1.052 & 1.221 & 4.728 \\
\hline External adjustment & & 0.0402 & 5.530 & 0.019 & 1.041 & 1.172 & 3.422 \\
\hline \multicolumn{8}{|l|}{ Log square root $(1 b)$ : } \\
\hline Internal adjustment & & 0.3182 & 6.973 & 0.008 & 1.375 & 1.880 & 5.809 \\
\hline External adjustment & & 0.3013 & 8.996 & 0.003 & 1.352 & 1.819 & 5.290 \\
\hline \multicolumn{8}{|l|}{ Log quadratic (1c): } \\
\hline \multirow[t]{2}{*}{ Internal adjustment: } & $\beta_{1}$ & 0.1377 & - & - & - & - & - \\
\hline & $\beta_{2}$ & -0.00327 & 8.309 & 0.0157 & 1.144 & 1.634 & 3.169 \\
\hline \multirow[t]{2}{*}{ External adjustment: } & $\beta_{1}$ & 0.1168 & - & - & - & - & - \\
\hline & $\beta_{2}$ & -0.00216 & 10.29 & 0.0058 & 1.121 & 1.531 & 4.721 \\
\hline \multicolumn{8}{|l|}{ Power (1d): } \\
\hline Internal adjustment & & 0.4268 & 6.957 & 0.008 & 1.344 & 1.976 & 4.364 \\
\hline External adjustment & & 0.4301 & 9.193 & 0.002 & 1.347 & 1.987 & 4.414 \\
\hline \multicolumn{8}{|l|}{ Linear relative rate $(1 \mathrm{e})$ : } \\
\hline Internal adjustment & & 0.1629 & 7.589 & 0.006 & 1.163 & 1.641 & 5.980 \\
\hline External adjustment & & 0.1441 & 9.127 & 0.003 & 1.144 & 1.567 & 5.405 \\
\hline \multicolumn{8}{|l|}{ Additive excess rate (2): } \\
\hline External adjustment & & 0.000088 & 2.943 & 0.09 & - & $-q$ & -9 \\
\hline
\end{tabular}

*Internal adjustment models: stratifying on time since first observed ( 3 levels), calendar time (9 levels), age ( 13 levels), and ethnicity (Hispanics $v$ other). External adjustment models: stratifying on ethnicity (Hispanics $v$ other) and time since first observed ( 3 levels) with external adjustment for age and calendar time using person-y (US rate). Cumulative exposure was classified in 50 levels in addition to the unexposed level.

tLikelihood ratio test for an exposure effect. (The log quadratic model test is based on two degrees of freedom.)

$\ddagger$ Estimate for cumulative exposure of $1.0 \mathrm{mg} / \mathrm{m}^{3} . \mathrm{y}$.

$\S$ Evaluated at mean and maximum estimated cumulative exposures of deaths from lung cancer.

१Not a relative rate model.

way et al noted that the prevalences of ever smoked in the highest two exposure strata were nearly identical (0.86 and 0.83$)$, but the rate ratios were very different (1.26 and 2.15$)$. They concluded that it was very unlikely that cigarette smoking could account for much of the observed association between mortality from lung cancer and cumulative exposure to silica. Therefore, confounding by cigarette smoking was not evaluated further in our analyses.

\section{Evaluation of confounding by exposure to asbestos} fibres

Checkoway et al found no evidence that exposure to asbestos accounted for the observed association between mortality from lung cancer and cumulative exposure to silica. Our analyses of their data also found no evidence of confounding by asbestos in the Poisson regression or Cox's proportional hazards models regardless of lag period; therefore, exposure to asbestos was not included in the models presented in this paper.

\section{Results}

POISSON REGRESSION ANALYSES AND COX'S PROPORTIONAL HAZARDS MODEL

Table 1 and figure 1 show the results of fitting the Poisson regression models described in the methods section to the data. Table 1 presents the log linear, log square root, log quadratic, power, linear relative rate, and additive excess rate forms of the Poisson regression models with a 10 year lag period. Models that used stratification to control calendar time and age confounding are referred to as having internal adjustment and models that used United States reference rates are described as having external adjustment (table 1). Relative risk estimates (rate ratios) are presented for $1.0 \mathrm{mg} / \mathrm{m}^{3}$.year compared with no exposure, as well as the

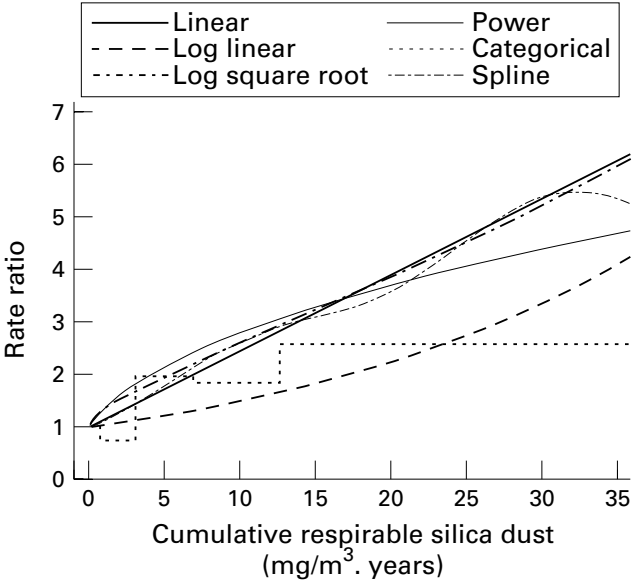

Figure 1 Rate ratio of mortality from lung cancer by cumulative exposure to silica. Poisson regression models with external adjustment for United States rates of death from lung cancer, 10 year lag.

mean and maximum cumulative exposure to silica for workers who died of lung cancer. Results of fitting those models (minus the log quadratic (1c) and additive excess rate (2) models) plus the categorical model and spline model are represented graphically in figure 1. The shape $(\alpha)$ model (not presented) produced an estimate for $\alpha$ close to 1.0 (0.997), which is essentially equivalent to a linear relative rate model. The tests for smooth departures from the log linear, log square root, and power models with cubic smoothing splines were not significant $(0.11<\mathrm{p}<0.36)$ providing direct support for these parametric models providing an adequate fit to the data. These results suggest that the other parametric relative rate models also provided adequate fits as their deviances were similarly small.

Exposure to respirable crystalline silica dust was a significant predictor $(p<0.05)$ of mortality from lung cancer in nearly all of the models 
Table 2 Predicted excess lifetime risks ${ }^{*}+$ of mortality from lung cancer assuming 45 years of respirable crystalline silica dust exposure (lagged 10 years) based on Poisson regression linear relative rate model with external adjustmentf

\begin{tabular}{lccccc}
\hline $\begin{array}{l}\text { Concentration } \\
\left(\mathrm{mg} / \mathrm{m}^{3}\right)\end{array}$ & $\begin{array}{l}\text { White } \\
\text { men }\end{array}$ & $\begin{array}{l}\text { White } \\
\text { women }\end{array}$ & $\begin{array}{l}\text { Black } \\
\text { men }\end{array}$ & $\begin{array}{l}\text { Black } \\
\text { women }\end{array}$ & $\begin{array}{l}\text { Total } \\
\text { population }\end{array}$ \\
\hline 0.001 & 0.4 & 0.2 & 0.4 & 0.2 & 0.3 \\
0.005 & 1.9 & 1.1 & 1.9 & 0.9 & 1.5 \\
0.01 & 3.8 & 2.2 & 3.7 & 1.7 & 2.9 \\
0.02 & 7.6 & 4.4 & 7.4 & 3.4 & 5.9 \\
0.03 & 11 & 6.7 & 11 & 5.2 & 8.8 \\
0.04 & 15 & 8.9 & 15 & 6.9 & 12 \\
0.05 & 19 & 11 & 18 & 8.6 & 15 \\
0.06 & 23 & 13 & 22 & 10 & 18 \\
0.07 & 26 & 15 & 25 & 12 & 20 \\
0.08 & 30 & 18 & 29 & 14 & 23 \\
0.09 & 34 & 20 & 33 & 15 & 26 \\
0.10 & 37 & 22 & 36 & 17 & 29 \\
\hline
\end{tabular}

${ }^{\star}$ Excess risk estimates are for 1000 workers. For example, the excess lifetime risk of lung cancer for white men at $0.05 \mathrm{mg} / \mathrm{m}^{3}$ of silica is 19 deaths per 1000 workers.

†Assuming that workers were exposed to a constant silica concentration for 45 years between the ages of 20 and 65, and accumulating annual risks up to age 85 .

‡US 1992 lung cancer mortalities.

evaluated. The linear relative rate model (1e) seemed to give the best fit in the Poisson regression analysis. The log linear model (1a) and additive excess rate models (2) seemed to provide the poorest fits. Results from the Cox's proportional hazards models were similar to the results of Poisson regression models. For example, the silica exposure-response estimates $\left(\beta_{1}\right)$ with the power model were $0.43(\mathrm{p}=0.002)$ and 0.48 ( $p=0.0009)$, respectively, for the Poisson and Cox's proportional hazards externally adjusted models. External adjustment substantially improved precision in both Poisson and Cox's proportional hazards models, and yielded estimates of the slopes similar to estimates from the internal adjustment models.

The linear relative rate model ( $1 \mathrm{e})$ predicted mortality rate ratios of about 1.6 for the mean cumulative exposure to respirable silica of the workers who died from lung cancer and 5.4 and 6.0 at the maximum exposure with external and internal adjustments, respectively. The log square root and power models predicted rate ratios ranging from 1.8 to 2.0 at the mean cumulative exposures to respirable silica and from 4.4 to 5.8 at the maximum exposure (table 1 ).

PREDICTION OF LIFETIME RISKS

Lifetime excess risks were calculated for log linear, log square root, power, and linear relative rate forms of Poisson regression and Cox's pro-

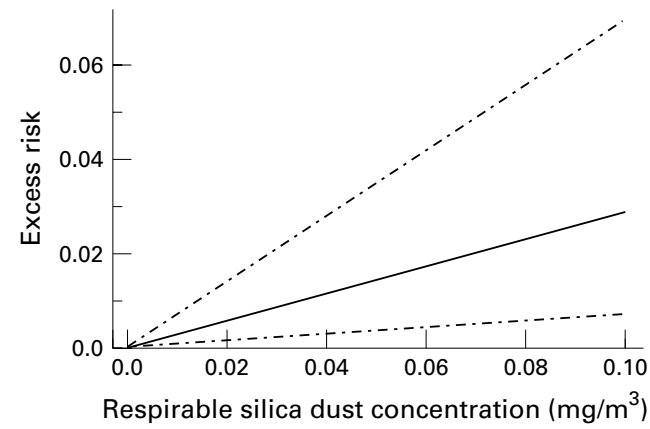

Figure 2 Estimated excess risk of lung cancer associated with up to 45 years of occupational exposure to respirable crystalline silica dust based on the linear relative rate model with a 10 year lag and United States total population mortality. (Two sided 95\% CIs are also shown.)

portional hazards models. Table 2 presents predicted lifetime excess risks of lung cancer from the best fitting model (linear relative rate Poisson regression model with external adjustment) for white men, white women, black women, black men, and the total population at various concentrations of crystalline silica dust. The estimates assume 45 years of exposure and incorporate a 10 year exposure lag. Because the cohort did not include women or non-white men, the lifetime risk estimates assume that those groups have the same response to silica exposure as white men. Point estimates of lifetime excess risk and two sided 95\% CIs are illustrated in figure 2. Other models, such as the power model, generally gave slightly higher risk estimates. At the National Institute for Occupational Safety and Health (NIOSH) recommended exposure limit (REL) of $0.05 \mathrm{mg} / \mathrm{m}^{3}$ for all forms of crystalline silica, ${ }^{16}$ the predicted lifetime excess risk for mortality from lung cancer in white men and black men is about $2 / 100(19 /$ $1000 ; 18 / 1000)$, and about $1 / 100(11 / 1000)$ in white women. The risks vary by sex and race because of differences in background rates for these groups.

\section{Discussion}

The results of our analyses are consistent with the significant exposure-response relation between exposure to crystalline silica and mortality from lung cancer previously reported by Checkoway et al. ${ }^{2}$ The exposure-response relation seemed to be linear on a relative risk scale.

Our risk estimates predict that 19 of every 1000 white male workers $(95 \%$ CI 5 to 46$)$

Table 3 Summary of data, methods, and lung cancer unit risk estimates for lifetime exposure to $1 \mu \mathrm{g} / \mathrm{m}^{3}$ of crystalline silica derived from risk analyses of toxicological or epidemiological data

\begin{tabular}{|c|c|c|c|c|}
\hline Reference & Data source & Exposure metric & Statistical model & Risk estimate \\
\hline Collins and Marty ${ }^{19}$ & $\begin{array}{l}\text { Geometric mean of risk estimates } \\
\text { from rat inhalation studies }{ }^{24-26}\end{array}$ & Respirable silica (quartz) particles & $\begin{array}{l}\text { Linearised multistage } \\
\quad \text { (GLOBAL 86) }\end{array}$ & $\begin{array}{l}2.9 \times 10^{-4}(95 \% \text { upper } \\
\text { confidence limit) (with surface } \\
\text { area correction factor) }\end{array}$ \\
\hline \multirow[t]{2}{*}{ Goldsmith et al ${ }^{18}$} & $\begin{array}{l}\text { Mortality study of diatomaceous } \\
\text { earth workers }{ }^{4}\end{array}$ & $\begin{array}{l}\text { Cumulative exposure to respirable } \\
\text { silica (exposure intensity } \times \text { years) } \\
\text { (mainly cristobalite) with } 15 \text { year lag }\end{array}$ & $\begin{array}{l}\text { Linearised multistage } \\
\quad \text { (GLOBAL 86) }\end{array}$ & $1.83 \times 10^{-7}$ \\
\hline & $\begin{array}{l}\text { Cohort mortality study of South } \\
\text { African gold miners }{ }^{21}\end{array}$ & Gold mining dust containing quartz & $\begin{array}{l}\text { Linearised multistage } \\
\quad \text { (GLOBAL 86) }\end{array}$ & $6.75 \times 10^{-5}$ \\
\hline Goldsmith et $a l^{18}$ & $\begin{array}{l}\text { Risk estimates from rat } \\
\text { inhalation studies }{ }^{24-26}\end{array}$ & Respirable silica (quartz) particles & $\begin{array}{l}\text { Linearised multistage } \\
\quad \text { (GLOBAL 86) }\end{array}$ & $\begin{array}{l}6 \times 10^{-3} \text { (95\% upper confidence } \\
\text { limit) (highest of } 5 \text { estimates) } \\
\text { (with surface area correction } \\
\text { factor) }\end{array}$ \\
\hline Rice et al (this study) & $\begin{array}{l}\text { Mortality study of diatomaceous } \\
\text { earth workers }{ }^{2}\end{array}$ & $\begin{array}{l}\text { Cumulative exposure to respirable silica } \\
\text { with } 10 \text { year lag (mainly cristobalite) in } \\
\mathrm{mg} / \mathrm{m}^{3} \text {.years }\end{array}$ & $\begin{array}{l}\text { Poisson regression: } \\
\text { linear relative rate }\end{array}$ & $3.8 \times 10^{-4}($ white men $)$ \\
\hline
\end{tabular}


exposed to respirable crystalline silica at the current NIOSH REL or OSHA standard ${ }^{17}$ for cristobalite (about $0.05 \mathrm{mg} / \mathrm{m}^{3}$ ) for their working lifetime (up to 45 years) would die from lung cancer related to silica. The estimate is essentially the same or increased with various exposure-response models. Risks were slightly lower for women.

COMPARISON WITH OTHER RISK ASSESSMENTS There are several other quantitative assessments of the exposure-response relation between exposure to crystalline silica dust and lung cancer where risk estimates could be calculated per $\mu \mathrm{g}$ of exposure to silica. Two assessments extrapolated to humans the risks from rat inhalation studies $^{24-26}$ to predict a "cancer potency slope" or inhalation unit risk for lifetime exposure to 1 $\mu \mathrm{g} / \mathrm{m}^{3}$ silica. ${ }^{18-20}$ Risk estimates from those assessments are within an order of magnitude of our risk estimate (table 3). Another assessment of cancer risk used exposure-response information reported in a cohort study of South African gold miners ${ }^{21}$ to derive cancer potency slopes with a linearised multistage (GLOBAL 86 program) model (table 3$).{ }^{18}$ The linearised multistage estimates were several orders of magnitude lower than our estimate, which might be explained by the fact that this method does not account for the less than lifetime follow up of the entire cohort of South African gold miners. The GLOBAL 86 model also tends to artificially shrink the variances when person-years are used in the denominator, resulting in an upper $95 \%$ $\mathrm{CI}$ that is too low. ${ }^{22}$ Our estimates may also be higher because of differences in (1) the cohorts, (2) surface properties, composition, and particle sizes of the dusts, (3) methods for estimating exposure, and (4) methods for estimating risk. ${ }^{23}$

COMPARISON WITH OTHER EPIDEMIOLOGICAL STUDIES

Although our study found a significant exposure-response relation between mortality from lung cancer and cumulative exposure to silica, some studies that examined cumulative exposure or surrogate measures of exposure, such as duration of employment, did not find a similar association. Steenland and Brown ${ }^{27}$ found no evidence of an exposure-response relation with mortality from lung cancer and cumulative exposure to dust or year of hire in a cohort of 3328 United States underground gold miners. A nested case-control analysis of 138 deaths from lung cancer among 2297 surface and underground gold miners in western Australia found that mortality from lung cancer was related to log total cumulative exposure to silica dust after adjustment for smoking (cigarette, pipe, or cigar) and for the presence of bronchitis at survey (relative rate of mortality from lung cancer: $1.31 ; 95 \%$ CI 1.01 to 1.70). After further adjustment for receipt of compensation awards for silicosis, the relative rate was not significant (relative rate of mortality from lung cancer: $1.20 ; 95 \%$ CI 0.92 to 1.56$){ }^{28}$ However, controlling for silicosis compensation and bronchitis may have masked an effect of silica because both are markers of exposure to silica.
A nested case-control study of 78 deaths from lung cancer in a cohort of 2260 white South African underground gold miners also controlled for silicosis (International Labour Organisation (ILO) category $\geqslant 1 / 1$ diagnosed up to 3 years before death of a matched case) in a model that included cumulative exposure to gold mine dust. ${ }^{29}$ Seventy eight deaths from lung cancer that occurred during 1970-86 were matched by year of birth with 386 control subjects from the same cohort of miners. Risk of mortality from lung cancer and a relation with cigarette smoking (pack-years), cumulative exposure to dust ( $\mathrm{mg} / \mathrm{m}^{3}$.years), years of underground mining, incidence of radiographic silicosis, and uranium production or uranium grade of the ore in the gold mine were analyzed with conditional logistic regression models. Measurements of radon daughters in the gold mines were not available. Cumulative exposure to dust and years of mining were strongly associated with risk of lung cancer until silicosis was included in the model, which resulted in disappearance of the exposure effects (relative risks of 1.0, 3.5 (95\% CI 0.7 to 16.8), 5.7 (95\% CI 1.3 to 25.8 ), and 13.2 (95\% CI 3.1 to 56.2 ) for $<6.5,6.5-20,21-30$, and $>30$ pack-years of smoking, respectively and 2.45 (95\% CI 1.2 to 5.2) for silicosis. ${ }^{29}$ The absence of a significant relation with exposure when silicosis was also controlled for is not surprising because of the high correlation of exposure to gold mine dust (containing about $30 \%$ crystalline silica) with silicosis. An earlier mortality study of the same cohort found a significant relation between cumulative exposure to dust (measured in particle-years) and lung cancer $(R R=1.023 ; 95 \%$ CI 1.005 to 1.042$) .{ }^{21}$

A nested case-control study of 52 deaths from lung cancer in a cohort of 5115 pottery workers found a positive exposure-response relation of mortality from lung cancer with mean concentration of silica (estimated daily 8 hour time weighted airborne concentrations in $\mu \mathrm{g} / \mathrm{m}^{3}$ ) (smoking adjusted $\mathrm{OR}=1.60,95 \% \mathrm{CI}$ 1.11 to 2.31 ; and $\mathrm{OR}=1.67,95 \%$ CI 1.13 to 2.47 , for 20 year and 0 year lag periods, respectively; $p<0.008$ for each lag period), but not with cumulative exposure to silica dust. ${ }^{30}$ However, mortality from lung cancer strongly declined with duration of employment (smoking adjusted $\mathrm{OR}=0.79$ for each 10 years duration; $95 \%$ CI 0.56 to 1.13 ) possibly indicating a large healthy worker survivor effect ${ }^{31}$ which, if not controlled for, would cause underestimation of effects of cumulative exposure. ${ }^{32}$ In our cohort, mean concentration of exposure to silica (cumulative silica exposure divided by duration) was not a significant predictor of mortality from lung cancer (Cox's proportional hazards model with external adjustment: rate ratio $=1.32$ predicted for a mean exposure concentration of $1.0 \mathrm{mg} / \mathrm{m}^{3} ; \mathrm{p}=0.318$ ).

A nested case-control study of 62 deaths from lung cancer among male pottery workers in China found that the risk of lung cancer was related to cumulative exposure to respirable silica, but testing for an exposure-response trend of the odds ratios adjusted for age and cigarette smoking over four exposure catego- 
ries was not significant ( $\mathrm{p}$ for trend $>0.05$ ). ${ }^{33}$ The researchers also investigated lung cancer and cumulative exposure to silica among male workers in Chinese iron-copper (74 cases), tungsten (93 cases), and tin mines (87 cases). The odds ratios increased significantly with increasing cumulative exposure to respirable silica for tin miners only ( $\mathrm{p}$ for trend=0.004). However, tin miners also had concurrent and highly correlated exposures to other carcinogens (arsenic: $r=0.80$, and polycyclic aromatic hydrocarbons: $r=0.80) .^{33}$

\section{STUDY LIMITATIONS}

Most existing epidemiological studies of exposure to silica and lung cancer have been hampered by inadequate data on confounding factors - such as smoking-and lack of adequate information on exposure for determining permissible worker exposure limits. ${ }^{34}$ This risk assessment was enhanced by the availability of good quality information about exposure to crystalline silica and dust containing silica and the absence of confounding by exposures to carcinogens that may be present in other industries with exposure to silica (radon progeny, arsenic, diesel exhaust, polycyclic aromatic hydrocarbons).

An evaluation of effects of confounding or interactions between exposure to silica dust and smoking was not performed because of considerable gaps in information about the cohort's smoking habits. Confounding would be possible if cigarette smoking was associated with potential exposure to silica dust in this cohort. Prevalence of cigarette smoking was unrelated to cumulative exposure in this cohort. $^{2}$ Also, internal adjustment models that compare exposed workers to workers with no exposure (table 1) are unlikely to be seriously confounded by differences in smoking habits. ${ }^{35}$ Moreover, smoking in exposure-response estimates is probably a negative confounder due to early removal of smokers from the population at risk. ${ }^{36}$ Our analyses compared rates within the cohort (table 1: internal comparisons), thus reducing the possibility of this bias. It is also possible that cigarette smoking and exposure to silica interact with each other to produce an effect that could not be assessed in our analysis.

The possibility of uncontrolled confounding of exposure to asbestos in this cohort ${ }^{2}$ has been debated in the scientific literature. ${ }^{37} 38$ The debate focused on 66 workers (including eight deaths from lung cancer) employed before 1930 who had excess mortality from lung cancer. The exposures to asbestos experienced by that group and their effects on the findings were uncertain, so analyses that excluded the workers first employed before 1930 were conducted. ${ }^{38}$ After exclusion of those workers, the results were nearly the same in the highest exposure stratum of cumulative exposure to crystalline silica $\left(>5.0 \mathrm{mg} / \mathrm{m}^{3}\right.$.years: rate ratio $=1.74)$ relative to the reference category $\left(<0.5 \mathrm{mg} / \mathrm{m}^{3}\right.$.years $)$ as after adjustment for exposure to asbestos (rate ratio=1.73). Analyses of standardised mortality ratio (SMR) conducted on the reduced cohort showed no evidence of confounding by asbestos. Checko- way et al also conducted a reanalysis ${ }^{3}$ of mortality from lung cancer among the diatomaceous earth workers who had worked for at least 1 day during the period $1942-87^{4}$ to focus on potential confounding from exposure to asbestos. The reanalysis was limited to men from the larger of two diatomite plants and for whom quantitative estimates of exposure to asbestos could be determined $(n=2266)$. The internal exposure-response analysis of mortality from lung cancer (52 deaths) showed an increasing trend with exposure to crystalline silica dust (as in the full cohort) and adjustment for exposure to asbestos made only minor differences in the relative risk estimates. Historical radiographic data were reviewed for pleural abnormalities (a marker of exposure to asbestos). The prevalence of pleural abnormalities among workers employed before 1930 $(4.2 \%)$ was similar to the prevalence in workers hired during 1930-9 (4.9\%), ${ }^{38}$ when asbestos was presumably not used in diatomaceous earth production. Checkoway et $a l^{\beta 8}$ concluded that confounding by exposure to asbestos remained a "very unlikely explanation" for the exposure response-relation of mortality from lung cancer with crystalline silica.

There are several other issues that could have affected our risk estimates.

Firstly, selection of an appropriate model is always a source of uncertainty for a risk analysis. We evaluated many models and based our choice of models on goodness of fit and not on any underlying mechanism for silica carcinogenicity, which has yet to be determined. It is worth noting that alternative models assessed in this analysis provided similar but higher risk estimates than the linear relative rate model. Another uncertainty is the validity of the estimates of cumulative exposure to silica, although the quality of the available data was high compared with data used in most retrospective cohort mortality studies.

A crucial issue is the applicability of these risk estimates to all work sites with exposure to respirable crystalline silica. Although quartz is the predominant form of crystalline silica in most workplaces, cristobalite is the predominant polymorph in the diatomaceous earth processing industry. ${ }^{2}$ However, it cannot be assumed that exposures to quartz or amorphous silica were absent. Epidemiological studies of workers in manufacturing environments that involve heating processes - such as ceramics, pottery, or brick manufacturing, or diatomaceous earth processing-where there may be exposure to two or more polymorphs of crystalline silica (mixed environments) have not reported risk estimates for exposures specifically to quartz or cristobalite. Our results reflect risks for exposure to crystalline silica dust that is mainly cristobalite. Early toxicological studies reported that cristobalite was more fibrogenic than quartz in experimental animals, ${ }^{39} 40$ and supported lower exposure limits for cristobalite and tridymite. ${ }^{41}$ Those findings have not been confirmed by results of epidemiological studies; however, there may be some evidence of increased mortality from lung cancer in industries with high temperature 
processes. ${ }^{30}{ }^{42}$ Furthermore, differences in the carcinogenic potential of various crystalline polymorphs have not been established ${ }^{1}$ and therefore cancer risks from workplace exposure to silica cannot yet be attributed or limited to a particular polymorph.

\section{Conclusions}

The results of our analyses suggest a positive, linear, and significant increase in risk of lung cancer with increasing estimated cumulative exposure to respirable crystalline silica dust (mainly cristobalite). A male worker exposed to $0.05 \mathrm{mg} / \mathrm{m}^{3}$ respirable silica dust containing cristobalite over a 45 year working lifetime has an increase in lifetime risk of lung cancer of about $2 \%$ above the background risk. The OSHA is currently considering the safety of its regulatory limits for exposure to crystalline silica. The OSHA generally seeks to control occupational exposures to carcinogens to concentrations that correspond to lifetime risks of less than $1 / 1000 .^{43}$ Our results suggest that workers exposed to respirable silica dust with cristobalite at the NIOSH REL and OSHA permissible exposure limit over a 45 year working lifetime have a risk of mortality from lung cancer much higher than $1 / 1000$ and therefore current standards may not be adequately protective. Also, workers exposed to respirable crystalline silica dust may develop silicosis and other diseases related to silica. The risk of nonmalignant respiratory disease in this cohort will be assessed in a subsequent analysis.

We thank Drs David Goldsmith, Paul Schulte, Loretta Schuman, and Kyle Steenland for their thoughtful and helpfu reviews of the manuscript, and Dr Nicholas Heyer for assistance with the data base.

1 International Agency for Research on Cancer. IARC monographs on the evaluation of carcinogenic risks to humans: silica, some silicates, coal dust, and para-aramid fibrils. Vol 68. Lyon, France: World Health Organization, IARC, 1997.

2 Checkoway H, Heyer NJ, Seixas NS, et al. Dose-response associations of silica with non-malignant respiratory disease and lung cancer mortality in the diatomaceous earth industry. Am f Epidemiol 1997;145:680-8.

3 Checkoway H, Heyer NJ, Demers PA, et al. Reanalysis of mortality from lung cancer among diatomaceous earth industry workers, with consideration of potential confounding by asbestos exposure. Occup Environ Med founding by $1996 ; 53: 645-7$.

4 Checkoway H, Heyer NJ, Demers PA, et al. Mortality among workers in the diatomaceous earth industry. $\mathrm{Br} \mathcal{F}$ Ind Med 1993;50:586-97.

5 Seixas NS, Heyer NJ, Welp EAE, et al. Quantification of historical dust exposures in the diatomaceous earth industry. Ann Occup Hyg 1997;41:591-604.

6 Preston DL, Lubin JH, Pierce DA, et al. Epicure user's guide. Seattle, WA: Hirosoft, 1993.

7 Wiggins CL, Becker TM, Key CR, et al. Cancer mortality among New Mexico's Hispanics, American Indians, and Non-Hispanic Whites, 1958-87. F Natl Cancer Inst 1993;85:1670-8

8 Breslow NE, Day NE. Statistical methods in cancer research. Vol 2. The Design and Analysis of Cohort Studies. Lyon, France: International Agency for Research on Cancer, 1987.

9 USDR97 Rates. Boston, MA: Department of Environmental Health, Harvard School of Public Health, 1997.

10 SAS Institute. SAS/STAT software: changes and enhancements through release 6.11. Cary, NC: SAS Institute, 1996:1104

11 Chambers JM, Hastie TJ. Statistical models in $S$ Pacific. Grove, CA: Wadsworth, 1992.

12 Mathsoft. S-plus 4 guide to statistics. Seattle, WA: Mathsoft, 1997.

13 Biological effects of ionizing radiation (BEIR) IV. Health risks of radon and other internally deposited alpha-emitters. Committee on the Biological Effects of Ionizing Radiation, Board of Radiation Effects Research, Commission on Life Sciences, National Research Council. Washington, DC National Academy Press, 1988.

14 National Center for Health Statistics. Vital statistics of the United States, 1992. Vol II. Mortality part A. Washington:
Public Health Service, 1996. (DHHS Publ No (PHS) 96-1101.)

15 Axelson O. Aspects on confounding in occupational health epidemiology [letter]. Scand $\mathcal{F}$ Work Environ Health 1978;4: 98-102.

16 National Institute for Occupational Safety and Health. Criteria for a recommended standard: occupational exposure to crystalline silica. Cincinnati, OH: US Department of Health, Education, and Welfare, Health Services and Mental Health Administration, NIOSH, 1974. (Publ No 75-120.)

17 Code of Federal Regulations 29 CFR 1910.1000, table Z-3. Washington, DC: US Government Printing Office, Office of the Federal Register 2000 .

18 Goldsmith DF, Ruble RP, Klein CA. Comparative cancer potency for silica from extrapolations of human and animal findings. Scand $\mathcal{f}$ Work Environ Health 1995;21(suppl 2):104-7.

19 Collins JF, Marty MA. Cancer risk assessment for crystalline silica to implement California's Hot Spots Act. Scand $\mathcal{f}$ Work Environ Health 1995;21(suppl 2):99-103.

20 Collins JF, Marty MA. Cancer risk assessment for crystalline silica. $\mathcal{f}$ Expo Anal Environ Epidemiol 1997;7: 359-65.

21 Hnizdo E, Sluis-Cremer GK. Silica exposure, silicosis, and lung cancer: a mortality study of South African gold miners. Br F Ind Med 1991;48:53-60.

22 Goldsmith DF, Hertz-Picciotto I. Criteria for conducting quantitative risk assessments for silica. $\mathcal{F}$ Expo Anal Environ Epidemiol 1997;7:367-75.

23 Rice FL, Stayner LT. Assessment of silicosis risk for occupational exposure to crystalline silica. Scand $\mathcal{f}$ Work Environ Health 1995;21 (suppl 2):87-90.

24 Dagle GE, Wehner AP, Clark ML, et al. Chronic inhalation exposure of rats to quartz. In: Goldsmith DF, Winn DM, Shy CM, eds. Silica, silicosis, and cancer: controversy in occupational medicine, cancer research monographs. Vol 2. New York: Praeger, 1986:255-66.

25 Holland LM, Wilson J, Tillery M, et al. Lung cancer in rats exposed to fibrogenic dusts. In: Goldsmith DF, Winn DM, Shy CM, eds. Silica, silicosis, and cancer: controversy in occupational medicine, cancer research monograph, Vol 2. New York: Praeger, 1986:267-79.

26 Muhle H, Takenaka S, Mohr U, et al. Lung tumor induction upon long term low level inhalation of crystalline silica. $\mathrm{Am}$ FInd Med 1989;15:343-46.

27 Steenland K, Brown D. Mortality study of gold miners exposed to silica and non-asbestiform amphibole minerals: an update with 14 more years of follow up. Am F Ind Med 1995;27:217-29.

28 de Klerk NH, Musk AW. Silica, compensated silicosis, and lung cancer in Western Australian goldminers. Occup Environ Med 1998;55:243-8.

29 Hnizdo E, Murray J, Klempman S. Lung cancer in relation to exposure to silica dust, silicosis, and uranium production in South African gold miners. Thorax 1997;52:271-5.

30 Cherry NM, Burgess GL, Turner S, et al. Crystalline silica and risk of lung cancer in the potteries. Occup Environ Med 1998:55:779-85.

31 Arrighi HM, Hertz-Picciotto I. The evolving concept of the healthy worker survivor effect. Epidemiology 1994;5:18996.

32 Park RM. The healthy worker survivor effect and mortality at two automotive engine manufacturing plants. Am f Ind Med 1996;30:655-63.

33 McLaughlin JK, Jing-Qiong C, Dosemeci M, et al. A nested case-control study of lung cancer among silica exposed workers in China. Br F Ind Med 1992;49:167-71.

34 Checkoway H. Methodological considerations relevant to epidemiology studies of silica and lung cancer. Appl Occup Environ Hyg 1995;10:1049-55.

35 Siemiatycki J, Wacholder S, Dewar R, et al. Smoking and degree of occupational exposure: are internal analyses in cohort studies likely to be confounded by smoking status? Am f Ind Med 1988;13:59-69.

36 Rothenbacher D, Arndt V, Fraisse E, et al. Early retirement due to permanent disability in relation to smoking in workers of the construction industry. F Occup Environ Med ers of the const

37 Gibbs GW. Re: "Dose-response associations of silica with nonmalignant respiratory disease and lung cancer mortality in the diatomaceous earth industry" [letter]. Am $\mathcal{F}$ Epidemiol 1998;148:307.

38 Checkoway H, Heyer NJ, Seixas NS, et al. The authors reply [letter]. Am f Epidemiol 1998;148:308-9.

39 Gardner LU. Reaction of the living body to different types of mineral dusts with and without complicating infection. New York: American Institute of Mining and Metallurgical Engineers, 1938. (Technical Publ No 929.)

40 King EJ, Mohanty GP, Harrison CV, et al. The action of different forms of pure silica on the lungs of rats. Brf Ind Med 1953;10:9-17.

41 Federal Register. OSHA comments from the June 19, 1988 final rule on air contaminants. Silica, crystalline: cristobalite. Federal Register 1989;54:2521. Available on NIOSH web site at http://www.cdc.gov/niosh/pel88/14464-46.html

$42 \mathrm{McDonald} \mathrm{C}$, Cherry N. Crystalline silica and lung cancer: the problem of conflicting evidence. Indoor Built Environment 1999;8:121-6.

43 Infante PF. Cancer and blue collar workers: who cares? New Solutions 1994;Winter:54-9. 